\title{
ESCOLAS EFICAZES NA EDUCAÇ̃̃O DE JOVENS E ADULTOS: ESTUDO DE CASOS NA REDE MUNICIPAL DO RIO DE JANEIRO
}

\author{
Jaqueline Luzia da Silva* \\ Alicia Maria Catalano de Bonamino** \\ Vera Masagão Ribeiro***
}

RESUMO: O artigo apresenta uma pesquisa que buscou identificar características de escolas que têm a capacidade de incidir positivamente no processo de alfabetização e na redução dos índices de evasão dos alunos da Educação de Jovens e Adultos (EJA). Foram analisadas três escolas da rede municipal do Rio de Janeiro que integram o Programa de Educação de Jovens e Adultos (PEJA) e têm bons indicadores de aprendizagem, permanência e aprovação, à luz da literatura sobre a pesquisa em eficácia escolar. Os resultados mostram que as escolas eficazes na modalidade EJA tomam atitudes explícitas para promover a assiduidade dos alunos. Estas instituições são organizadas quanto à disciplina e orientação curricular, além de contar com equipes pedagógicas (diretores, coordenadores, orientadores e professores) integradas e focadas no ensino e na aprendizagem. E mantêm altas expectativas em relação ao desempenho e à trajetória escolar dos alunos. Palavras-chave: Educação de Jovens e Adultos. Eficácia Escolar. Programa de Educação de Jovens e Adultos do Município do Rio de Janeiro (PEJA).

\footnotetext{
* Doutora em Educação pela Pontifícia Universidade Católica do Rio de Janeiro (PUC-Rio); Técnica em Assuntos Educacionais da Faculdade de Letras da Universidade Federal do Rio de Janeiro (UFRJ) e Professora alfabetizadora do Centro Municipal de Referência de Educação de Jovens e Adultos (CREJA/SME/RJ). E-mail: jackluzia@yahoo.com.br

** Doutora em Educação pela Pontifícia Universidade Católica do Rio de Janeiro (PUC-Rio); Professora Associada do Departamento de Educação da Pontifícia Universidade Católica do Rio de Janeiro (PUC-Rio). E-mail: alicia@puc-rio.br * * Doutora em Educação pela Pontifícia Universidade Católica de São Paulo (PUC-SP); Pesquisadora e Coordenadora geral da Ação Educativa - Assessoria Pesquisa e Informação. E-mail: vera.masagao.ribeiro@gmail.com
} 


\section{SCHOOLS SUCCESSFUL IN THE EDUCATION OF JUVENILES AND ADULTS: CASE STUDIES FROM THE CITY OF RIO DE JANEIRO}

ABSTRACT: The present work describes research carried out in order to identify a number of school characteristics having a positive influence on the literacy process as well as on reduction of school drop-out rates from EJA (young people and adult education). Three municipal schools from Rio de Janeiro city, participating in PEJA (young people and adult education program), were investigated. According to the school effectiveness survey these institutions presented high levels of learning, improved grades and better attendance. The results show that the schools successfully following the EJA program, demonstrate unambiguously an attitude promoting students' diligence and also count on integrated pedagogical staff (directors, coordinators, counselors and teachers) with a special focus on learning and teaching. Not to mention the fact that they are organized on the basis of, both: behavioral standards and national curriculum. Furthermore, they maintain high expectations in relation to the students' performance as well as their predicted school paths.

Keywords: Juvenile and Adult Education. School Effectiveness. Successful School. Young People. Juvenile and Adult Education Program of Rio de Janeiro City (PEJA).

\section{Introdução}

As estatísticas e a pesquisa sobre Educação de Jovens e Adultos (EJA) no Brasil mostram que os baixos níveis educacionais da população jovem e adulta são produto não apenas das condições sociais e econômicas que dificultam o acesso da população de baixa renda à escola, mas também de fatores intraescolares que comprometem a aprendizagem e desestimulam a permanência dos jovens e adultos nos programas a eles destinados (HADDAD; DI PIERRO 2000b). Essa situação impõe grandes responsabilidades aos sistemas educacionais, que precisam buscar formas mais adequadas de oferecer oportunidades de escolarização para esse público. Para o campo da pesquisa, coloca-se a urgência de que se produzam indicações sobre os melhores caminhos para promover a permanência e a aprendizagem de um segmento populacional reincidentemente excluído do sistema educacional. A presente pesquisa orientou-se por esse objetivo, tratando de identificar as características pedagógicas e de gestão de três escolas públicas do município do Rio de Janeiro que oferecem as fases iniciais da EJA e apresentam taxas de evasão e índices de aprendizagem que as destacam positivamente do conjunto da rede. 
O texto está organizado em cinco seções. Na primeira, descrevem-se, sucintamente, a trajetória e as principais características do Programa de Educação de Jovens e Adultos (PEJA) da Secretaria Municipal de Educação do Rio de Janeiro (SME-Rio). Na seção seguinte, são apresentados resultados de pesquisas sobre eficácia escolar no Brasil e no exterior que serviram como referência para o desenho deste estudo. Na terceira seção, são descritas a metodologia e as categorias de análise; na quarta, apresentam-se os principais resultados. $\mathrm{Na}$ seção final, tecem-se comentários e apontam-se sugestões para as políticas de EJA.

\section{0 contexto do programa}

O Programa de Educação de Jovens e Adultos da Rede Municipal de Educação do Rio de Janeiro (PEJA) teve origem no Projeto de Educação Juvenil (PEJ) planejado em 1983, durante a primeira gestão de Leonel Brizola no estado (1982/1986), sob a coordenação de Darcy Ribeiro, educador e vice-governador do estado. Em 1985, o PEJ foi municipalizado, passando então para a responsabilidade da SME-Rio. Inicialmente, o projeto era dirigido aos jovens das classes populares egressos do ensino regular, na faixa etária de 15 a 20 anos, e funcionava em 20 Centros Integrados de Educação Pública (CIEPS), ofertando a alfabetização (FÁVERO; ANDRADE; BRENNER, 2007).

A partir de 1987, em resposta às reivindicações dos profissionais de educação e dos alunos, o projeto foi ampliado e passou a garantir a continuidade de estudos correspondente ao primeiro segmento do ensino fundamental. O curso organizou-se, então, em dois blocos de aprendizagem, destinados à alfabetização e à pós-alfabetização. Apesar dessa mudança, o PEJ não podia atestar a escolaridade de seus alunos, pois não era reconhecido pelo Conselho Municipal de Educação. Em 1988, o PEJ passou a conviver com o ensino regular noturno, que atendia jovens trabalhadores com até 20 anos de idade impossibilitados de frequentar o horário diurno e que desejavam completar a escolaridade básica.

Nesse mesmo ano, a promulgação da Constituição Federal de 1988 estendeu o direito ao Ensino Fundamental a todas as pessoas, independentemente da idade. Dois anos mais tarde, era extinta a Fundação Educar, sucedânea do Mobral, iniciativa federal que nascera na forma de 
campanha de alfabetização e, progressivamente, passara a fomentar o atendimento de jovens e adultos nas primeiras séries do ensino fundamental, em parceria com os municípios. A medida correspondia à tendência de descentralização da oferta de educação para jovens e adultos, num contexto em que os municípios assumiam, crescentemente, a responsabilidade por atender à demanda de jovens e adultos interessados em retomar sua escolarização (HADDAD; DI PIERRO, 2000a). Em 1997, os municípios brasileiros já eram responsáveis por $40 \%$ das matrículas na modalidade EJA correspondente às primeiras séries do Ensino Fundamental e, em 2005, por 80\%. Nas séries finais desse nível de ensino na EJA, a participação dos municípios na oferta, apesar de menor, também cresceu de forma acelerada, de $17 \%$ para $44 \%$, no mesmo período (BRASIL, 2008).

A Lei de Diretrizes e Bases da Educação Nacional de 1996 (Lei 9.394/96) reconheceu a Educação de Jovens e Adultos como modalidade da Educação Básica, integrando-a organicamente ao sistema de ensino. Entretanto, os preceitos constitucionais ainda não se concretizaram integralmente nas políticas públicas. Ao ser instituído o Fundo Nacional de Desenvolvimento do Ensino Fundamental e Valorização do Magistério (FUNDEF), mecanismo criado para garantir aos estados e municípios os recursos necessários para a ampliação da oferta de Ensino Fundamental, a modalidade EJA foi excluída. A EJA ficou dependente de transferências voluntárias da União para estados e municípios, por meio do Fundo Nacional para o Desenvolvimento da Educação (FNDE). Esse fundo teve papel relevante na oferta de recursos para a EJA até 2006.

Para o Projeto de Educação Juvenil do Rio de Janeiro, em 1996, com a parceria estabelecida entre a Secretaria Municipal de Educação e o Ministério da Educação, foram destinadas verbas que possibilitaram iniciativas significativas, entre as quais a realização do I Encontro de Educação de Jovens e Adultos do Município do Rio de Janeiro. Nesse encontro, foi sinalizada a necessidade de revisão da faixa etária abarcada pelo programa, de modo a incluir os adultos a quem a Constituição estendera o direito ao Ensino Fundamental. Respondendo a uma demanda manifesta, muitas escolas já abriam suas portas aos adultos na condição de alunos ouvintes.

Em 1998, a SME-Rio apresentou ao Conselho Municipal de Educação uma proposta para a implantação do segundo segmento do 
Ensino Fundamental no PEJ (PEJ II) e a regulamentação do mesmo. No ano seguinte, foi dado caráter terminal ao Projeto, com garantia de documentação retroativa a 1998 a todos aqueles que haviam frequentado seus cursos, sendo estabelecida a faixa etária de 14 a 22 anos para o PEJ I e de 14 a 25 anos para o PEJ II. No ano de 2005, em resposta a novas demandas e de acordo com as leis em vigor, foi publicado pelo Conselho Municipal de Educação o Parecer 06/2005 que, entre outras alterações, estabeleceu o nome Programa de Educação de Jovens e Adultos (PEJA), em substituição à designação usada até então (FÁVERO; ANDRADE; BRENNER 2007). A mudança consagrada na nova denominação impulsionou a ampliação da oferta de vagas, o oferecimento da modalidade no horário diurno, o estabelecimento de parcerias com a sociedade civil, o reconhecimento do Centro Municipal de Referência de Educação de Jovens e Adultos (CREJA), unidade dedicada exclusivamente à oferta de EJA e à redefinição de matrizes curriculares para o programa (PREFEITURA, 2005).

Em julho de 2008, o PEJA passou a compor o Departamento de Educação de Jovens e Adultos da Secretaria Municipal, o que significa que hoje ocupa um lugar institucionalizado e permanente na estrutura dessa secretaria, referendado pelo Plano Municipal de Educação. Atualmente, o PEJA funciona em 115 escolas da rede pública municipal, majoritariamente no horário noturno, atendendo pessoas jovens e adultas, a partir de 14 anos completos, sem limite superior de idade. No ano de 2007 estavam matriculados mais de 33 mil alunos. A Tabela 1 mostra o crescimento exponencial do atendimento no PEJA, no período de 1998 a 2007.

TABELA 1. Evolução das Matrículas no PEJA - 1998-2007

\begin{tabular}{c|c} 
Ano & Número de alunos matriculados \\
\hline 1998 & 2968 \\
1999 & 7892 \\
2000 & 11576 \\
2001 & 15603 \\
2002 & 23091 \\
2003 & 26065 \\
2004 & 31473 \\
2005 & 32482 \\
2006 & 33547 \\
2007 & 33130
\end{tabular}

Fonte: SME - Assessoria Técnica de Planejamento, 2007 
De acordo com seus pressupostos pedagógicos, o PEJA organiza-se em blocos de aprendizagem, e não em séries, de modo a adequar o ensino ao ritmo de aprendizado dos alunos. Isso significa que não é necessário que o aluno curse um ano letivo para ser promovido. Cada segmento (PEJA I e PEJA II) possui dois blocos, divididos em três trimestres letivos. O primeiro bloco do PEJA I destina-se a alunos que nunca frequentaram ou estavam afastados da escola e não concluíram a alfabetização inicial; o segundo recebe os alunos promovidos do primeiro e novos matriculados que dominam a alfabetização inicial. Em ambos, dispõe-se de matérias interdisciplinares específicas para essa modalidade de ensino e a docência é realizada por um único professor. Nos últimos anos, o público do PEJA I também passou a incluir, ao lado de jovens e adultos que nunca frequentaram ou que se afastaram da escola, os adolescentes oriundos das Classes de Progressão' do Ensino Regular. No PEJA II, os alunos contam com professores das disciplinas Língua Portuguesa, História e Geografia, Matemática, Ciências e Língua Estrangeira Moderna ou Linguagens Artísticas, responsáveis pela elaboração das apostilas utilizadas ao longo das três unidades de progressão em que se organiza cada bloco.

Tendo em vista a fragilidade institucional e a descontinuidade dos programas de EJA no país, são aspectos distintivos do PEJA sua continuidade ao longo de mais de duas décadas, atravessando diferentes gestões municipais, assim como a integração orgânica de suas turmas às escolas onde funciona. Uma única equipe de direção se responsabiliza tanto pelo Ensino Regular quanto pela EJA, as duas modalidades fazem parte do Sistema de Controle Acadêmico e do calendário de matrículas da rede, além de utilizar as mesmas salas de aula e outros espaços da escola (sala de leitura, laboratório de informática, etc.). O PEJA, hoje, certifica jovens e adultos ao final do Ensino Fundamental, atende nos horários noturno e diurno, possui uma série de classes anexas ${ }^{2}$ e um centro de referência, o CREJA, que se dedica unicamente a essa modalidade, com um regime flexível ${ }^{3}$. Além disso, o programa tem se aberto ao atendimento aos alunos deficientes, matriculados como alunos integrados nas classes de EJA. Uma ação destinada à melhoria das condições de oferta do programa foi a incorporação da EJA no Núcleo Curricular Básico Multieducação - responsável pelas orientações curriculares da rede -, que contou com a participação de comissões de professores do 
programa, com a responsabilidade de proposição curricular e elaboração de orientações pedagógicas.

A avaliação no PEJA é idealizada e realizada pelos professores regentes e pelos integrantes das equipes pedagógicas das escolas. As equipes do nível central e das Coordenadorias Regionais de Educação (CREs) ${ }^{4}$ acompanham esse processo por meio de visitas às escolas, dando orientação às ações de formação e produzindo relatórios-síntese dos resultados por unidade, por regional e no conjunto da rede. O processo de ensino e aprendizagem conta com parâmetros curriculares que indicam os objetivos a serem alcançados ao final de cada bloco. Esses parâmetros norteiam a avaliação ao longo do ano letivo e, principalmente, servem à tomada de decisão quanto à progressão ou à retenção dos alunos, ao final dos blocos. A cada Conselho de Classe (COC), os parâmetros são retomados para que os professores reconheçam os principais objetivos do bloco em que atuam.

Apesar da estruturação pedagógica do programa e de sua organicidade dentro da rede, o PEJA também apresenta taxas importantes de evasão e retenção, tal como ocorre na modalidade EJA de modo geral. No bloco I, o índice de alunos que ficam retidos por não alcançarem os parâmetros estabelecidos gira em torno de um terço, ao final de cada ano letivo. Com relação à evasão, os índices ficam em torno de $20 \%$ a cada trimestre. Entretanto, algumas escolas, distribuídas em diversas regiões da cidade, conseguem resultados significativamente melhores, atendendo um perfil de alunos semelhante ao das demais. Diante dessa constatação, considerou-se que tais escolas favoreceriam a identificação de características pedagógicas ou de gestão que poderiam estar associadas à sua eficácia.

\section{A pesquisa sobre eficácia escolar}

A abordagem das características dessas escolas que se destacam das demais quanto às taxas de reprovação e desempenho dos alunos tomou como referência as pesquisas sobre escolas eficazes. Essa perspectiva de pesquisa se firmou nos Estados Unidos como uma reação às descobertas de Coleman (1966) e suas visões pessimistas a respeito da capacidade das escolas de fazerem a diferença sobre o desempenho dos estu- 
dantes, uma vez que este estaria determinado dominantemente pela origem social. Contrapondo-se a essa perspectiva, as pesquisas sobre escolas eficazes tratam de identificar fatores intraescolares que têm impacto significativo sobre a aprendizagem dos alunos, conseguindo diminuir as desigualdades dadas pela condição social familiar de origem deles.

No Brasil, grande parte dos estudos sobre escolas eficazes foi desenvolvida com base em dados do Sistema de Avaliação da Educação Básica (Saeb) e de sistemas estaduais de avaliação, como o Sistema Mineiro de Avaliação da Educação (Simave) ou o Sistema de Avaliação de Rendimento Escolar do Estado de São Paulo (Saresp). De forma geral, esses estudos apresentam evidências convergentes com estudos internacionais sobre o papel positivo da escola e dos recursos escolares, quando efetivamente utilizados (BARBOSA; FERNANDES, 2001). No nível da turma, características do trabalho dos professores e de sua interação com os alunos também aparecem com tendo poder explicativo do desempenho escolar (BONAMINO; FRANCO; FERNANDES, 2002). Quanto à organização e à gestão da escola, as pesquisas reportam resultados positivos para a liderança do diretor e para o comprometimento coletivo do corpo docente com o aprendizado dos alunos (SOARES 2002, 2003; ALBERNAZ; FRANCO; ORTIGÃO, 2004). O clima da escola orientado para as exigências acadêmicas do processo de ensino e de aprendizagem (FRANCO; MANDARINO; ORTIGÃO, 2001) e o estilo pedagógico docente também evidenciam efeito positivo sobre o desempenho dos alunos (FRANCO; BONAMINO, 2005).

Soares e Alves (2003) analisam as desigualdades de desempenho escolar entre alunos discriminados por raça, utilizando os resultados dos testes para a $8^{a}$ série do Ensino Fundamental do Saeb 2001. A pesquisa revela que se as diferenças entre brancos e pardos podem ser parcialmente reduzidas por fatores escolares, tais como envolvimento do diretor, equipamentos da escola, qualificação e salário dos professores, lição de casa realizada pelos alunos, existência de livros na casa dos alunos, etc., essa mesma situação não é observada quando se compara brancos e negros.

Se já dispomos de um acervo razoável de pesquisas sobre escolas eficazes no ensino regular, os estudos sobre eficácia escolar em EJA não tiveram ainda desenvolvimento semelhante. Certamente, isso se deve à ausência de avaliações em larga escala que, como o Saeb, gerem dados 
sobre o desempenho dos alunos e sobre as condições de oferta educacional, os professores, os alunos e diretores das escolas de EJA. Pesquisas desse tipo se tornam cada vez mais importantes, tendo em vista que a qualidade e a equidade são questões ainda não resolvidas na educação brasileira e que têm consequências sobre o aumento da procura por vagas na EJA.

Em âmbito internacional, a quantidade de estudos sobre eficácia de programas de educação de adultos também é relativamente restrita. A informalidade e a baixa institucionalidade dos programas, aliadas a restrições no investimento nessa modalidade, podem explicar tal situação. $\mathrm{Na}$ última década, entretanto, especialmente nos Estados Unidos e na Inglaterra, houve forte incentivo para a realização de pesquisas que produzissem evidências sólidas sobre intervenções educacionais eficazes. Sob essa influência, ao lançar, em 2001, um programa nacional de educação de adultos, o Skills for Life, o governo britânico encomendou uma revisão de pesquisas que pudesse prover evidências sobre as melhores práticas pedagógicas a serem adotadas (TORGERSON et al., 2004). O levantamento privilegiou pesquisas conduzidas segundo métodos experimentais, mas sistematizou também as evidências extraídas de estudos baseados em modelos correlacionais. Os autores realizaram levantamentos em grandes bases de dados relacionadas à área da educação de adultos: o Educational Resources Information Center (ERIC), The Campbell Collaboration's Social, Psychologial, Educacional and Criminological Trials Register e o Social Science Citation Index (SSCI). A seleção foi feita somente entre estudos em língua inglesa realizados a partir de 1980; foram identificadas 4.555 referências de artigos contendo as palavras-chave (literacy, numeracy e adult education), entre os quais somente 59 eram estudos de natureza experimental ou comparativa realizados com o rigor metodológico requerido e inseridos no escopo de interesse.

Segundo Torgerson et al. (2004), as pesquisas experimentais comprovam que a participação em programas de alfabetização tem efeitos positivos no nível de aprendizagem de alunos adultos, mas que poucas metodologias conseguiram provar maior eficácia que outras, exceto uma delas, baseada no diálogo entre professor e alunos ao longo da leitura de textos (reciprocal teaching). Os estudos que exploraram o uso de tecnologias de informação e comunicação (TIC) não conseguiram identificar melhores resultados de aprendizagem nos programas que utilizam tais 
meios, quando comparados com outros que empregam meios de instrução convencional. Com base na revisão de estudos correlacionais, os autores destacam como evidências relevantes na dimensão pedagógica o fato de que exercícios de consciência fonológica, análise de palavras e fluência, além do ensino explícito de estratégias de compreensão de textos, têm efeitos positivos no desempenho dos alunos. Quanto às características dos programas, destacam o fato de que mostraram melhores resultados aqueles que contam com professores habilitados ou monitores que recebem assistência constante na sala de aula, aqueles que têm expectativas altas quanto ao desempenho dos alunos e os que oferecem certificação e encaminham os alunos para prosseguimento de estudos.

Para fazer frente à escassez de evidências baseadas em pesquisas sobre as melhores práticas no campo da educação de adultos, o National Development Centre for Adult Literacy and Numeracy (NRDC), da Universidade de Londres, empreendeu o estudo Effective Teaching and Learning Reading. A pesquisa investigou a aprendizagem de leitura numa amostra de 454 alunos e 59 salas de aula, envolvendo mais de 470 horas de observação. Um dos seus objetivos foi a compreensão dos fatores escolares que contribuem para uma aprendizagem bem-sucedida (BROOKS et al., 2007). A pesquisa foi conduzida entre 2003 e 2006, por meio de testes aplicados aos alunos, entrevistas e observação das estratégias utilizadas pelos professores em sala de aula, resultando em achados relevantes sobre a aprendizagem dos alunos, sobre práticas pedagógicas eficazes e sobre a formação dos professores. As principais conclusões do estudo apontam que, nas escolas consideradas eficazes, os alunos trabalham mais em grupo ou em pares. Os maiores progressos foram alcançados por mulheres e por trabalhadores e aspectos como a idade, a etnia e o fato de o inglês ser ou não a primeira língua do aluno não influenciam o progresso e os resultados dos alunos. A pesquisa constatou, ainda, aumento na autoestima e na autoconfiança entre os estudantes e os egressos.

A pesquisa verificou que as práticas pedagógicas adotadas com maior frequência pelos professores eram a avaliação da leitura, a discussão de vocabulário, o uso de jogos com palavras (quebra-cabeças, lista de palavras e pesquisa de palavras) e de dicionário para a procura do significado de palavras. Todavia, um dos limites apontados pela pesquisa é que, durante as aulas, raramente era incentivada a fluência em leitura, o ensino recíproco entre os alunos e a compreensão pelos alunos das estratégias de 
ensino utilizadas pelos professores. De acordo com o estudo, a prática da leitura em voz alta é fundamental para o progresso da aprendizagem, sendo que sua ausência ajuda a explicar os baixos índices de aprendizagem da leitura verificados em alguns dos casos estudados.

Por sua vez, as entrevistas com os professores evidenciaram as críticas do corpo docente à pressão, à burocratização e à rigidez das propostas curriculares, bem como sua inadequação às necessidades dos alunos adultos. Os docentes salientaram, no entanto, que o currículo gerava "boas ideias" e ajudava na elevação da autoconfiança dos professores. Algumas recomendações da pesquisa giram em torno das competências de ensino de leitura que deveriam ser enfatizadas na formação inicial e continuada dos professores para que estes adquirissem as competências específicas para o ensino junto à população adulta. Entre estas competências, apontam a fluência verbal, a compreensão das estratégias utilizadas pelos professores, o ensino recíproco dos alunos e as experiências diversificadas com a linguagem.

A pesquisa recomenda, ainda, que, na formação inicial e continuada dos professores, se enfatize, também, o ensino de formas mais adequadas de utilização dos materiais curriculares, além de estratégias de ensino da leitura adaptadas às necessidades dos alunos. Além disso, o estudo destaca a importância de levar os alunos a se sentirem responsáveis pela sua própria aprendizagem, desenvolvendo condições de estudo autônomo e a distância, com o apoio das tecnologias de informação e comunicação (TICs) e, principalmente, mediante a oferta de oportunidades frequentes de trabalho em grupo na sala de aula.

Ainda que incipiente no campo da EJA, as pesquisas sobre escolas eficazes, de maneira geral, sugerem uma série de aspectos que merecem serem considerados para verificar, em diferentes contextos, quais são os determinantes de um ensino que promove a aprendizagem e a permanência dos jovens e adultos na escola. Nessa literatura, foi possível encontrar sistemas de construtos que ajudaram na estruturação metodológica da pesquisa realizada no PEJA, ainda que esta tenha guardado características próprias, relacionadas ao contexto, às especificidades e à história do próprio programa. 


\section{Critérios de seleção e análise das escolas eficazes no PEJA}

Para selecionar as escolas a serem estudadas com vistas a identificar as características que promovem sua eficácia junto ao público da EJA, foram utilizados dados oficiais do PEJA sobre evasão e repetência contidos no Relatório de Desempenho do ano de 2006. Como o foco do estudo no nível da alfabetização inicial já estava previamente definido, foram selecionadas as escolas de cada uma das CREs que apresentavam os mais baixos índices de evasão e os maiores índices de promoção entre os Blocos 1 e 2 do PEJA I. Em relação ao desempenho dos alunos, foram consideradas as avaliações pedagógicas realizadas pelos próprios professores e registradas por meio de conceitos ${ }^{5}$, uma vez que os alunos do programa não são submetidos a avaliações padronizadas. Depois de selecionadas as escolas com melhor desempenho nesses dois quesitos - índices de evasão e conceitos atribuídos nas avaliações de desempenho dos alunos feitas pelos professores -, em cada uma das CREs em que se estrutura o programa, foram selecionadas as três melhores dentre elas. Assim, foi possível selecionar boas escolas situadas em diferentes regiões da cidade: duas delas situam-se em bairros da Zona Norte - Oswaldo Cruz e Vila da Penha - e outra, num bairro na Zona Oeste - Bangu. As três escolas selecionadas oferecem um total de seis turmas de PEJA I, duas de Bloco 1 e quatro de Bloco 2. Cada turma possui, aproximadamente, trinta alunos matriculados, com idades variadas. As escolas contam com Diretor, Diretor Adjunto e Coordenador Pedagógico. Uma delas conta com um Professor Orientador ${ }^{6}$, função exclusiva para o PEJA.

Um dos principais desafios metodológicos dos estudos de escolas eficazes é o isolamento de variáveis relacionadas à origem socioeconômica dos alunos, que têm normalmente forte peso em seu desempenho escolar. Somente controlando essas variáveis é possível identificar, efetivamente, a contribuição específica de fatores intraescolares ou o valor agregado pela escola. No caso da EJA, em especial no nível da alfabetização inicial, já temos, pela própria característica da modalidade, uma triagem quanto ao perfil socioeconômico dos estudantes, o que torna o grupo bastante homogêneo nesse aspecto. Ainda assim, vale a pena ressaltar que os bairros onde se situam as três escolas selecionadas são conhecidos na cidade como bairros periféricos, onde residem, majoritariamente, famílias de baixa renda, o que constitui mais um indício de que o 
bom desempenho dos alunos dessas escolas não se devia a características socioeconômicas diferenciadas do entorno ou de suas famílias, mas sim às características intraescolares que a pesquisa pretendia desvelar. No entanto, para a caracterização socioeconômica foi também aplicado um questionário aos alunos.

Para a caracterização das escolas selecionadas, foram estudados documentos como os projetos político-pedagógicos, os registros de classe, os quadros de desempenho do ano em que foi realizado o trabalho de campo (2008) e os instrumentos de avaliação utilizados pelas professoras. A massa de dados mais significativa, entretanto, foi obtida por meio de entrevistas, grupos focais com os alunos e observação direta do cotidiano escolar e das salas de aula do PEJA I, durante oito meses, cinco dias por semana, totalizando 450 horas ou 150 dias letivos de observação.

Em sintonia com as pesquisas sobre escolas eficazes, a observação pretendeu obter uma visão abrangente do cotidiano escolar, buscando recolher informações não só sobre atividades realizadas na sala de aula, mas também sobre a infraestrutura, o clima acadêmico e disciplinar da escola e a liderança pedagógica da gestão. Assim, além de um número significativo de aulas, foram observadas sessões de conselhos de classe, os Centros de Estudos (encontros pedagógicos realizados periodicamente entre a coordenação e os professores), a sala dos professores e os corredores da escola.

Com relação à infraestrutura, foram observados o estado de conservação do prédio, as condições de funcionamento das salas de aula, a limpeza, a segurança e o estado de conservação dos equipamentos. Nas salas de aula das seis turmas do PEJA I, foram observados aspectos como a organização da rotina e do espaço, as atividades didáticas propostas, os materiais utilizados, as estratégias de mobilização e motivação, o apoio docente ao desenvolvimento cognitivo dos alunos, a relação afetivo-social entre professores e alunos, a interação dos alunos entre si e com as atividades escolares. Na Tabela 2 é possível perceber como foram conduzidas as observações das aulas nas escolas selecionadas: 
TABELA 2. Construtos observados durante as aulas

\begin{tabular}{|c|c|}
\hline $\begin{array}{c}\text { CONSTRUTOS } \\
\text { A - Aspectos preliminares da sala de aula } \\
\text { e dos atores sociais diretamente } \\
\text { envolvidos }\end{array}$ & $\begin{array}{c}\text { DIMENSÕES } \\
\text { - Tempo de duração da aula } \\
\text { • Número de alunos em sala } \\
\text { - Características gerais dos alunos } \\
\text { - Características gerais do professor } \\
\text { - Tempo em que o professor atua com esta turma }\end{array}$ \\
\hline $\begin{array}{l}\text { B - Aspectos organizacionais ou } \\
\text { de gestão da sala de aula }\end{array}$ & $\begin{array}{c}\text { - Tempo real de ensino-aprendizagem } \\
\text { - Rituais de início da aula } \\
\text { • Organização da rotina } \\
\text { • Organização espacial da classe }\end{array}$ \\
\hline $\begin{array}{c}\text { C - Atividades didáticas ou situações } \\
\text { de ensino-aprendizagem }\end{array}$ & $\begin{array}{c}\text { - Dinâmica inicial para introdução do tema da aula } \\
\text { • Proposição de temas pelo professor } \\
\text { • Atividades desenvolvidas durante a aula } \\
\text { - Estratégias metodológicas utilizadas pelo professor } \\
\text { (gerais; de leitura e escrita; de matemática, etc.) } \\
\text { - Práticas escolares a que os alunos foram submetidos } \\
\text { • Uso de materiais e recursos durante a aula } \\
\text { • Rituais de término da aula }\end{array}$ \\
\hline $\begin{array}{l}\text { D - Ambiente ou clima escolar e } \\
\text { aspectos ligados ao desenvolvimento } \\
\text { afetivo-social dos alunos }\end{array}$ & $\begin{array}{l}\text { - Cumprimento das regras preestabelecidas } \\
\text { - Clima da sala de aula e manejo do grupo } \\
\text { - Apoio do professor ao desenvolvimento afetivo-social dos alunos } \\
\text { - Apoio do professor ao desenvolvimento cognitivo e verbal dos alunos } \\
\text { - Desenvolvimento de postura autônoma e formação de hábitos de estudo } \\
\text { - Reação dos alunos frente aos temas, atividades e instruçães do professor }\end{array}$ \\
\hline
\end{tabular}

As observações desses aspectos foram complementadas pelas entrevistas realizadas junto às professoras, às diretoras, às coordenadoras pedagógicas ou à professora orientadora das escolas. Nessas, procurou-se verificar suas visões sobre os objetivos da escola, a organização escolar, as estratégias de orientação pedagógico-educacional, o clima organizacional, o perfil dos alunos e as expectativas que recaem sobre eles, o relacionamento entre a escola e a comunidade e a infraestrutura. Focalizaram-se questões como a quantidade de alunos por turma, a presença de alunos com deficiência nas turmas, os projetos desenvolvidos, as estratégias de recuperação paralela, o funcionamento da orientação pedagógica, as alterações no projeto original do programa, a utilização de sala de leitura e da sala de informática, o uso dos materiais didáticos fornecidos pelo PEJA, a seleção dos professores, a participação dos professores nas ações de formação continuada oferecidas pela SME, os critérios de avaliação dos professores, entre outros.

Junto aos alunos, além do questionário para caracterização socioeconômica, que foi respondido com auxílio da pesquisadora e das 
professoras, realizaram-se também grupos focais. As questões levantadas nos grupos focais foram planejadas a partir do roteiro de entrevista das professoras, coordenadores e dos diretores, para que se conhecesse a percepção dos alunos a respeito dos temas pesquisados, visando a complementar as outras técnicas utilizadas na pesquisa. O roteiro do grupo focal da pesquisa compreendeu tanto aspectos escolares quanto sociais de apropriação da leitura e da escrita e da relação com a aprendizagem.

A abordagem analítica foi a do estudo de caso comparativo; buscou-se compreender as características das três escolas nas suas particularidades e comunalidades, tendo em vista também os aspectos reportados como significativos pelas pesquisas e pela literatura sobre escolas eficazes. O método de estudo de caso comparativo foi escolhido em razão de possibilitar a identificação de conexões entre os diversos aspectos analisados, que fazem de cada uma das unidades investigadas uma escola diferente, sem deixar, no entanto, de revelar também os traços recorrentes e mais essenciais que podem ser associados aos resultados positivos obtidos pelas três escolas.

\section{Os achados da pesquisa}

\section{Características e tipo de atuação da direção}

Uma característica encontrada nas escolas pesquisadas diz respeito ao fato de a gestão escolar estar centrada na dimensão pedagógica da escola, e não apenas na administrativa. Nestas escolas, a aprendizagem é enfatizada no trabalho da direção e da equipe técnico-pedagógica. Também foi possível perceber forte afinação entre as visões e opiniões da direção, das coordenadoras pedagógicas e das professoras. Esse aspecto indica que há amplo compartilhamento de visões e concepções sobre o que é necessário fazer para que os alunos aprendam, o que certamente favorece o processo de ensino e aprendizagem e a progressão dos alunos. Constata-se que, nas escolas investigadas, as diretoras e diretoras adjuntas sabem o que acontece nas salas de aula, conhecem os alunos, têm contato direto com a coordenação pedagógica, estão presentes na escola à noite, participam dos Conselhos de Classe e procuram saber quais as principais dificuldades enfrentadas por alunos e professores. 


\section{Características do ambiente físico e organizacional}

O fato de existirem regras claras e explícitas é outro aspecto que chama a atenção nessas escolas. Trata-se de escolas de EJA que, surpreendentemente, têm regras rígidas com relação ao comportamento dos alunos e às normas escolares. As regras incidem sobre a exigência do uso do uniforme, do cumprimento dos horários de chegada e saída (os portões são trancados após determinado horário e só os trabalhadores, com comprovação, podem chegar atrasados), a conservação da limpeza da escola, a proibição do uso do boné, de minissaias, de chinelos, do celular, do fumo nos espaços da escola, entre outras. Contudo, essas regras, informadas aos alunos desde o primeiro dia de aula, não são motivo de conflito ou transgressão. Ao contrário, na fala dos alunos, as regras são importantes para o convívio e o cuidado com a escola e para a qualidade das relações que se estabelecem nesse espaço.

Além disso, as três escolas pesquisadas mostram preocupação com as faltas dos alunos. São escolas que estabeleceram como estratégia a busca do retorno dos alunos faltosos, ligando para suas casas ou enviando recados pelos colegas. Uma das escolas, inclusive, enviava carta social para os alunos, convidando-os a retornarem às aulas. Essas atitudes parecem surtir um efeito importante, tanto por aumentar a assiduidade quanto por sinalizar aos alunos o reconhecimento e o interesse da equipe escolar pelo seu processo de aprendizagem. A motivação dos alunos, o aproveitamento do tempo e o clima acadêmico favorável, com atividades de recuperação paralela, são outras das características apresentadas pelas escolas pesquisadas que contribuem para o bom desempenho e minimizam a evasão dos alunos do PEJA.

\section{Características dos professores,} envolvimento com escola e alunos, formas de avaliação, formação

$\mathrm{Na}$ pesquisa, não pode ser observado se a qualificação dos professores interfere nos resultados positivos apresentados, mas verificou-se que as professoras buscam se especializar na área da educação, em cursos de graduação e pós-graduação.

Nas escolas pesquisadas, também são altas as expectativas sobre o desempenho dos alunos. Ainda que estes tenham histórias de vida mar- 
cadas pelo fracasso escolar, pela falta de crença em si mesmos, as professoras acreditam na aprendizagem dos alunos, sabem que eles são capazes e conseguirão progredir na escola. Isso é percebido por meio do incentivo dado aos alunos, recorrentemente, pelas professoras, para que não desistam, para que se esforcem, para que continuem estudando e desenvolvam sua aprendizagem.

O profissionalismo e a responsabilidade de todos os envolvidos são revelados pelo compromisso das professoras com o trabalho realizado, na ênfase nos aspectos cognitivos, na preocupação com o cumprimento do programa de ensino, no controle sobre as técnicas de ensino e no fato de as professoras serem assíduas e os alunos não ficarem sem aula. Essas características também aparecem na atuação das coordenadoras pedagógicas, que apoiam, sistematicamente, as necessidades dos professores.

O desenvolvimento profissional docente é verificado por meio da experiência que as professoras têm no magistério, do tempo de atuação na escola e da formação inicial e continuada que recebem, por iniciativa da CRE e/ou da SME.

Além disso, chama a atenção a afetividade entre alunos e professores e entre os alunos, o que contribui para a permanência destes na escola, pois garante o envolvimento e o compromisso de professores e alunos com o ensino e a aprendizagem.

A avaliação e o monitoramento da aprendizagem são muito importantes para a eficácia escolar e fazem a diferença com relação aos níveis de desempenho e índices de evasão das escolas. A pesquisa verificou que as avaliações frequentes do progresso dos alunos do PEJA, de maneira processual e cotidiana, permitem um olhar diferenciado dos professores sobre a aprendizagem dos alunos, e o controle dos resultados ao longo do ano letivo, dando origem a atividades de recuperação paralela, auxílio individualizado, aceleração dos estudos e tomada de decisões mais conscientes sobre a aprovação ou não dos alunos para o bloco seguinte.

\section{Características das práticas de sala de aula}

Os objetivos educacionais das escolas pesquisadas dão prioridade à compreensão da leitura, expressão de ideias, raciocínio lógico, autonomia e criatividade dos alunos. Essas habilidades são fortemente valori- 
zadas pelas escolas, o que se reflete no trabalho em sala de aula, no cuidado com o planejamento e nas atividades de ensino e aprendizagem.

No PEJA I, o trabalho em grupos ou duplas também está presente nas salas de aula, mas com intensidade variável nas turmas e escolas observadas, dependendo do estilo pedagógico do docente. De forma geral, entretanto, todas as professoras incentivam os alunos a prestarem ajuda aos colegas.

A troca pedagógica entre os professores do PEJA I e os do PEJA II é uma prática presente. Regularmente, foi possível observar que as professoras do primeiro segmento conversavam com as colegas do segundo segmento, mostrando produções dos alunos, questionando sobre os conteúdos curriculares necessários para o bloco seguinte. Essas iniciativas parecem redundar em maior segurança das professoras do PEJA I com relação ao trabalho pedagógico e contribuir para a permanência dos alunos na escola, pois o trabalho realizado previamente pelas professoras parece lhes dar as ferramentas necessárias para a continuidade e a progressão nos estudos.

Quanto às práticas pedagógicas realizadas pelas professoras, foi possível observar a ênfase na realização de tarefas e exercícios individuais; na revisão de conteúdos quando não foram assimilados satisfatoriamente pelos alunos; no uso do quadro branco para cópias, resolução de exercícios e tarefas; e em atitudes como o esclarecimento de termos e conceitos, na formulação de perguntas para os alunos e na frequência com que as professoras respondem as dúvidas dos alunos.

Entre as práticas menos presentes ou mesmo ausentes no cotidiano dessas salas de aula estão a produção ou a leitura de textos com temas escolhidos pelos alunos; o uso de vídeos e/ou computador; e o hábito de contar histórias aos alunos.

O planejamento das aulas é uma característica variável entre as professoras pesquisadas. O que se verificou é que algumas professoras fazem um planejamento detalhado, por aula e semanal, com pesquisa de materiais, dedicação e aproveitamento dos conhecimentos prévios de seus alunos, enquanto outras (duas, neste caso) não fazem planejamento sistematizado das aulas. E são estas professoras, do Bloco 1, que apresentam maiores dificuldades com o trabalho em sala de aula, o que foi observado durante a pesquisa de campo e também apontado nas entrevistas. 
Um delas diz que não costuma fazer o planejamento sistematizado de aulas porque sabe que se planejar muito não usará o que preparou. Ela possui folhas guardadas em seu armário, que utiliza com os alunos de acordo com a necessidade, aleatoriamente. Trata-se de exercícios, geralmente retirados de coleções didáticas. Outra professora também afirma que de nada adianta preparar muito e não utilizar o que preparou. Então, no final de semana, pensa em um apanhado de conteúdos que serão trabalhados, mas sua aula acontece a partir do dia a dia, do que vai surgindo, do que vai sendo trazido pelos alunos, além de utilizar exercícios retirados de coleções didáticas voltadas para EJA. Entretanto, embora essas professoras encontrem maiores dificuldades no trabalho cotidiano, apresentam resultados positivos quanto à aprendizagem e à permanência de seus alunos na escola.

Foi possível verificar, ainda, que não há uma abordagem metodológica seguida por todas as professoras. O que se percebe são abordagens híbridas por parte das professoras, que não seguem uma linha específica, teórica ou prática, que possa caracterizar sua prática em tradicional ou construtivista, por exemplo. Esta observação coincide com a posição das professoras que evitaram se autoclassificar dentro de uma abordagem específica de alfabetização, o que parece indicar que os resultados das escolas pesquisadas independem da metodologia de alfabetização adotada.

Um fator ainda não resolvido diz respeito à integração efetiva dos alunos com deficiência. Apenas duas das turmas pesquisadas possuíam alunos integrados, embora sem um trabalho direcionado para a aprendizagem. As professoras mostraram não ter os conhecimentos necessários para atuar com esses alunos de maneira satisfatória. Ainda que fossem auxiliados por outros profissionais, esses alunos estavam há mais de um ano no mesmo bloco e não tinham perspectiva de avanço para os blocos seguintes.

\section{Visões dos alunos sobre a escola}

É interessante ouvir os relatos dos alunos, pois, para eles, a aprendizagem vai além da apreensão dos conteúdos escolares. Muito mais do que melhorar a leitura e a escrita, esses alunos alcançam uma mudança de vida. Eles lidam com a realidade de outra maneira e atribuem isso à contribuição da escola. Falar melhor, ter mais paciência, ajudar os filhos, 
aprimorar o trabalho não são conteúdos explícitos da EJA, mas, para esses alunos, foi na escola que "aprenderam" tais atitudes.

Entre os conhecimentos que os alunos relatam estar aprendendo - além da leitura e da escrita - estão a melhoria das condições para fazer transações bancárias; fazer compras; produzir listas; pegar ônibus lendo o letreiro; ler placas de rua; assinar o próprio nome; se expressar melhor oralmente; ler a Bíblia; escrever e ler bilhetes; ler o jornal; ler livros; fazer palavras cruzadas; fazer cálculos; ler cardápios; ter mais paciência com os filhos; passar trocos; cuidar do lixo, da água e dos alimentos; conviver melhor com os outros e, inclusive, para a melhoria da memória.

As perspectivas dos alunos em relação a sua própria aprendizagem e ao futuro também foram verificadas pela pesquisa. Boa parte delas está no desejo de continuar estudando e trabalhando, já verificado no questionário por eles respondido. Nas entrevistas, os alunos deixam claro que, entre as principais perspectivas, está a mudança de profissão ou aquisição de melhor posição no trabalho; o desejo de adquirir competências para a vida social, como tirar carteira de habilitação; deixar de sentir vergonha, ocasionada pelo fato de não ser alfabetizado(a); cursar o Ensino Médio, fazer um curso superior e ler com mais fluência.

Uma das maiores expectativas dos alunos entrevistados, em todas as escolas, é o desejo de serem aprovados para os blocos ("séries") seguintes. Nas falas dos alunos aparece sempre uma forte preocupação com o fato de não conseguirem aprender algo trabalhado pela professora em sala de aula e isso ocasionar a reprovação e a permanência no bloco. Alguns alunos afirmam que não sabem se serão aprovados e, ao mesmo tempo, justificam esse fato dizendo que não estão preparados e por isso querem continuar no bloco em que se encontram. Ser aprovado significa avançar na escola e na vida, caminhar para frente, evoluir. Ainda que não tenham essa certeza, os alunos orgulham-se de estar estudando e do que estão aprendendo. Sentem-se mais capazes e mais felizes por estarem estudando.

As principais dificuldades encontradas na escola, tanto com relação à aprendizagem quanto com relação à vida cotidiana, foram trazidas pelos alunos nos grupos focais. Eles apresentam como principais dificuldades relacionadas aos problemas de aprendizagem a idade, o cansaço, a falta de tempo para estudar em casa, a dependência de outras pessoas para 
ler correspondências e documentos pessoais e o preconceito social sofrido por estar estudando em idade avançada.

Nos relatos da maioria dos alunos, aparece a dificuldade de escrever, realizar as atividades de matemática: contas de divisão, problemas e cálculos; a vergonha de usar o uniforme escolar na rua; a distância entre a escola e seu local de trabalho ou sua casa; a vergonha de não compreender o que as pessoas com mais estudo falam; problemas de memória; não ter com quem deixar os filhos pequenos; não ter o apoio da família para retornar aos estudos; o cansaço físico à noite; a longa carga horária de trabalho; a vergonha de pedir para que outras pessoas leiam correspondências e documentos; serem enganados nas compras e em trocos de dinheiro; e a quantidade de responsabilidades diárias.

\section{Principais conclusões}

A pesquisa pode verificar um número significativo de características em comum e também algumas diferenças entre as escolas. A gestão participativa e voltada para o pedagógico é comum às três escolas. Nelas, diretoras e coordenadoras estão preocupadas com a aprendizagem dos alunos, tanto ou mais do que com as questões burocráticas e administrativas. E isso é demonstrado tanto nas entrevistas quanto nas observações do trabalho de campo. A preocupação de entrar em contato com os alunos que começam a se ausentar das aulas, por telefone, correspondência ou por meio de outros alunos conhecidos também é comum às três e evidencia a importância de que haja intencionalidade explícita em evitar a evasão. Além disso, por meio de atitudes como essa, os alunos podem reconhecer o interesse e o valor que a equipe escolar atribui ao processo educativo e a cada aluno, fator que também parece ser bastante relevante para a sua permanência na escola. Essa não é, entretanto, uma atitude comum nas escolas que ofertam EJA, uma vez que se entende como esperado o fato tanto de o aluno não comparecer assiduamente às aulas quanto o de se evadir.

A ênfase das escolas pesquisadas recai sempre sobre a aprendizagem, principalmente a aprendizagem da leitura e da escrita. Contudo, não são escolas em que somente os aspectos acadêmicos são observados. Destacam-se o acolhimento, o respeito e os vínculos que são estabeleci- 
dos entre a equipe pedagógica e os alunos, o que os faz se sentirem bem no espaço da escola.

Os resultados mais recorrentes das pesquisas sobre escolas eficazes são confirmados a partir da pesquisa no PEJA. Neste estudo, porém, foi possível observar que o bom desempenho dos alunos parece resultar de uma conjunção de vários fatores. Assim, não basta, por exemplo, que as escolas tenham uma série de normas e regras de organização para que alcancem resultados positivos, é também necessário que esse conjunto de normas faça sentido e seja respeitado por todos. Cumpridas às regras, é preciso que haja ainda organicidade e constância nas atividades de ensino e um ambiente acolhedor e estimulante que favoreça a presença e o engajamento dos estudantes. Nas escolas pesquisadas, esse clima organizacional favorável é criado a partir da integração da equipe pedagógica voltada para uma proposta pedagógica comum.

Os resultados obtidos por esse estudo junto a três escolas que ofertam a EJA na rede municipal do Rio de Janeiro sugerem que essa é uma linha de pesquisa a ser melhor explorada no campo da EJA. Sugere também que o empenho e a integração da equipe escolar é condição essencial para a melhoria da qualidade educativa. Nesse sentido, pode-se afirmar que o fortalecimento das equipes escolares deve ser o foco dos esforços das políticas voltadas para esse fim.

Em síntese, os achados deste estudo confirmam que a capacidade de a escola propiciar a aprendizagem dos alunos passa pela manutenção de uma infraestrutura adequada às aulas noturnas para jovens e adultos, com a disponibilidade de recursos pedagógicos diversificados, bem como pela existência de metas e objetivos claros e voltados para aprendizagens significativas; e a presença de professores que participam das ações de formação continuada e supervisão pedagógica, além de um clima acadêmico favorável à aprendizagem; com conteúdos curriculares que façam sentido para os alunos; e de um corpo docente que troque entre si práticas de sala de aula e saberes pedagógicos, apoiado pela coordenação pedagógica. Depende, ainda, da presença de professores que tenham expectativas positivas quanto à aprendizagem de seus alunos, com vistas à superação das dificuldades encontradas e que conduzam avaliações frequentes do progresso dos alunos, de modo a monitorar e garantir a melhoria no desempenho e na qualidade do ensino oferecido. 
No entanto, não se pode esperar que as escolas consigam, em números massivos, esse grau de integração e qualificação do seu trabalho, sem que haja o empenho significativo dos gestores educacionais e profissionais atuando nos órgãos centrais e regionais das redes de ensino para criar as condições, os parâmetros e os estímulos para que as equipes escolares ampliem suas expectativas quanto ao desempenho dos alunos e consigam chegar, mais e mais, perto dos objetivos educacionais que se propõem. 


\section{Referências}

ALBERNAZ, A.; FERREIRA, F.; FRANCO, C. Qualidade e equidade no ensino fundamental brasileiro. Pesquisa e Planejamento Econômico, v. 32, n. 3, Rio de Janeiro, IPEA, 2002. ALBERNAZ, A.; FRANCO, C.; ORTIGÃO, M. I. Características escolares que melhoram o desempenho dos alunos da $4^{a}$ série do Ensino Fundamental: evidências a partir dos dados do SAEB-2001. Rio de Janeiro: PUC-Rio, 2004.

BARBOSA, M. E. F. e FERNANDES, C. A escola brasileira faz diferença? Uma investigação dos efeitos da escola na proficiência em Matemática dos alunos da $4^{a}$ série. In: FRANCO, C. (Org.). Promoção, ciclos e avaliação educacional. Porto Alegre: ArtMed, 2001.

BONAMINO, A.; FRANCO, C.; FERNANDES, C. Repetência escolar e apoio social familiar: um estudo a partir dos dados do SAEB 2001. PUC-Rio/LAED/INEP: Relatório Técnico, 2002.

BRASIL Ministério da Educação. Informe nacional para a VI Conferência Internacional de Educação de Adultos. Brasília: MEC, 2008.

BROOKS, Greg; BURTON, Maxine; COLE, Pam; SZCZERBINSKI, Marcin. Effective Teaching and Learning Reading. National Research and Development Centre for adult literacy and numeracy. Londres: NRDC, 2007.

COLEMAN, J. S. Equality of Education Opportunity. Office of Education, U. S. Washington D. C., 1966.

FÁVERO, Osmar; ANDRADE, Eliane Ribeiro; BRENNER, Ana Karina. Programa de Educação de Jovens e Adultos (PEJA). In: HADDAD, Sérgio. Novos caminhos em Educação de Jovens e Adultos - EJA. São Paulo: Global, 2007.

FRANCO, Creso; BONAMINO, Alicia. A pesquisa sobre característica de escolas eficazes no Brasil: breve revisão dos principais achados e alguns problemas em aberto. Educação On-Line: Revista do Programa de Pós-graduação em Educação. n. 1, PUC-Rio, 2005.

FRANCO, Creso; MANDARINO, M.; ORTIGÃO, M. I. Projeto Pedagógico de Escola Promove Qualidade e Equidade em Educação? Revista UNDIME-RJ, VII, n. 2, p. 30-46, 2001.

HADDAD, Sérgio (Coord.). Educação de Jovens e Adultos no Brasil (1986-1998). Brasília, DF: MEC/INEP/COMPED, 2002.

HADDAD, Sérgio; DI PIERRO, Maria Clara. Escolarização de jovens e adultos. Revista Brasileira de Educação, São Paulo, n. 14, p. 108-130, maio/ago. 2000a.

HADDAD, Sérgio; DI PIERRO, Maria Clara. Aprendizagem de jovens e adultos: avaliação da década da educação para todos. São Paulo em Perspectiva. São Paulo, v. 14, n. 1, p. 29-40, mar. 2000b.

JENCKS, C. et. al. Inequality: A Reassessment of the Effect of Family and Schooling in America. New York, Basic, 1972.

MACHADO, Flora Prata. Aluno do PEJ: quem é você, por onde você andou? 132p. Dissertação (Mestrado em Educação) PUC-Rio. Rio de Janeiro, 2004.

MACHADO, Flora Prata. A Educação de Jovens e Adultos na Rede Pública Municipal do Rio de Janeiro. In: PREFEITURA DA CIDADE DO RIO DE JANEIRO. Secretaria Municipal de Educação. Documento de orientações sobre o funcionamento do PEJA, 2006.

PREFEITURA DA CIDADE DO RIO DE JANEIRO. Secretaria Municipal de 
Educação. Documento de orientaçoes sobre o funcionamento do PEJA, 2006.

PREFEITURA DA CIDADE DO RIO DE JANEIRO. Secretaria Municipal de Educação. Parecer n. 06 de 25 de janeiro de 2005. Aprova alterações no funcionamento do PEJ e dá outras providências.

PREFEITURA DA CIDADE DO RIO DE JANEIRO. Secretaria Municipal de Educação. Parecer n. 03 de 07 de abril de 1999. Aprova o Projeto de Educação Juvenil nas suas etapas PEJ I e PEJ II.

SOARES, José Francisco (Coord.). Escola eficaz: um estudo de caso em três escolas públicas de ensino do Estado de Minas Gerais. Belo Horizonte: GAME/FaE/UFMG, 2002. SOARES, José Francisco. Avaliação de Escolas de Ensino Básico. In: FREITAS, Luiz Carlos de. (Org.). Avaliação de Escolas e Universidades. Campinas: Komedi, 2003, v. 1, p. 59 92.

SOARES, José Francisco; ALVES, Maria Teresa Gonzaga. Desigualdades Raciais no Sistema Brasileiro de Educação Básica. Educação e Pesquisa (USP), São Paulo, v. 29, p. 147 165, 2003.

TORGERSON, Caroline et al. Adult literacy and numeracy interventions and outcomes: a review of controlled trials. Londres: NRDC, 2004. 


\section{Notas}

1 A Classe de Progressão consistia numa turma especial para a qual eram enviados, até o ano de 2006, os alunos que, ao final do terceiro ano do primeiro Ciclo de Formação (equivalente à segunda série no ensino seriado), não conseguiam alcançar a alfabetização necessária para serem aprovados e promovidos para a terceira série ou que ingressavam na escola com nove anos ou mais. O Ciclo de Formação foi a proposta pedagógica adotada pela Secretaria Municipal do Rio de Janeiro, a partir do ano 2000. Durante seis anos, a Rede Municipal trabalhou com o regime de Ciclo (somente o $1^{\circ} \mathrm{Ciclo}$, com duração de três anos) e séries (da $3^{\mathrm{a}}$ a $8^{\mathrm{a}}$ série). Em 2007, com a expansão do segundo e do terceiro Ciclos (abrangendo todo o Ensino Fundamental), as Classes de Progressão deixaram de existir na Rede e os alunos foram remanejados para turmas de acordo com a faixa etária e, eventualmente, encaminhados para o PEJA (aqueles com 14 anos ou mais).

2 No ano de 2003, foram implantadas 156 classes anexas, compondo o Programa Aumento de Escolaridade (uma parceria entre o PEJA/SME e a Secretaria Municipal de Assistência Social). Nesse programa, foram certificados cerca de cinco mil alunos de diferentes comunidades atendidas pelo Programa Favela-bairro (MACHADO, 2006).

3 O CREJA funciona durante todo o dia, das 7 horas da manhã às 22 horas, com 42 turmas. Esse período está dividido em seis turnos, de duas horas cada. Esse horário especial permite aos alunos uma flexibilidade de complementação de carga horária de estudo, pois, além de frequentarem as aulas no seu horário destinado, os alunos também podem assistir às aulas em outros horários, como complementação, sempre que necessitarem e desejarem.

4 A Rede Municipal do Rio de Janeiro é composta por dez CREs, que fazem o acompanhamento às escolas (supervisão, orientação, coordenação e planejamento).

5 Estes conceitos estão especificados na Resolução SME-Rio n. 776, de 8 de abril de 2003.

6 O Professor Orientador - função presente em boa parte das escolas com PEJA - atua como um coordenador pedagógico exclusivo do PEJA. Essa função só existe nas escolas com PEJA noturno, nas quais haja seis ou mais turmas de PEJA.

Recebido: 06/02/2011

Aprovado: 05/03/2012

Contato:

Ação Educativa, Assessoria, Pesquisa e Informação

Rua General Jardim, 660

Vila Buarque

CEP 01223-010

São Paulo, SP

Brasil 